\title{
Evaluation of crowdsourcing logistics service quality based on entropy weight method and analytic hierarchy process
}

\author{
Mian Fu' ${ }^{1}$, Dan dan Wang ${ }^{1}$ \\ ${ }^{1}$ Business School, Xinhua University of Anhui Province, Hefei, China
}

\begin{abstract}
Crowdsourcing logistics mode is the product of sharing economy by integrating idle resources to reduce the operating cost and improve the efficiency of enterprises. Taking the service quality of crowdsourcing logistics as the research object, this paper analyzes the key influencing factors of the service quality of crowdsourcing logistics, and constructs a crowdsourcing logistics service quality evaluation index system with 4 first level indicators and 15 second level indicators. At the same time, by using AHP and entropy weight method, The paper select dada and Renren express to evaluate their service quality. Through the case analysis of the two express companies' service quality, the paper draw the conclusion that safety is still the most concerned factor in the evaluation of crowdsourcing logistics service quality at this stage.
\end{abstract}

\section{INTRODUCTION}

Crowdsourcing logistics mode is the product of sharing economy by integrating idle social resources to reduce operating costs and improve work efficiency. At the same time, the above advantages also lead to a lot of service quality problems, such as the uneven quality of part-time express personnel, no one to take orders for goods, leakage of customer identity information, damage to goods and so on, which leads to the decline of customer satisfaction, the decrease of enterprise loyalty, the increase of customer service complaints and so on. Therefore, improving the service quality of crowdsourcing logistics has become the focus of enterprises, and the service quality has also become the key point of sustainable development of crowdsourcing logistics enterprises. Therefore, how to use quantitative and objective evaluation method to evaluate the service quality of crowdsourcing logistics, so as to improve the service quality of crowdsourcing logistics enterprises is very important [1-5].

\section{CONSTRUCTION OF EVALUATION INDEX SYSTEM OF CROWSSOURCING LOGISISTICS SERVICE QUALITY}

\subsection{Basic Principles of Constructing Evaluation Index System}

When selecting the evaluation index, we need to select the index based on the characteristics of crowdsourcing logistics service and customer perceived service. The selected index should be the key and representative factor that affects the quality of crowdsourcing logistics service.
(1) Principle of universality

Although the crowdsourcing logistics enterprises are different, the services they can provide should have the characteristics of crowdsourcing logistics services. Therefore, the selected evaluation index system of crowdsourcing logistics service quality should be able to evaluate the service quality of all crowdsourcing logistics enterprises, and its evaluation index system should not be unique to a single enterprise.

(2) Systematic principle

When constructing the evaluation index system of crowdsourcing logistics service quality, we should consider the characteristics of crowdsourcing logistics service, establish the evaluation index system of crowdsourcing logistics service quality through the way of level by level, and refine the index layer by layer to get the secondary index. In the process of index classification, we should pay attention to the systematicness of crowdsourcing logistics service index system, that is, to avoid the overlapping of different elements in the same level index, and to have independence and logicality between different levels.

(3) Principle of operability

In the selection of evaluation indicators, we need to take into account the operability and feasibility of the indicators, and we can not consider the indicators that do not have operability, so as to ensure that such indicators can make the evaluation easy to implement.

(4) The principle of comprehensiveness

The principle of comprehensiveness refers to that when selecting the evaluation index of crowdsourcing logistics service quality, we should fully consider all the key factors that can affect the quality of crowdsourcing logistics service. Try to make sure that the selected evaluation index can fully reflect the evaluation of

*fm15395112646@126.com, wangdandan@sina.com 
crowdsourcing logistics service quality, and avoid the one sidedness and irrationality of the evaluation index.

\subsection{Construction of evaluation index system}

According Based on the previous research results of crowdsourcing logistics service quality evaluation, this paper constructs the evaluation index system of canteen supplier selection from four aspects of product quality, product price, service capacity and production capacity, and selects four secondary indexes and 15 tertiary indexes to form the evaluation index system, as shown in Figure 1.

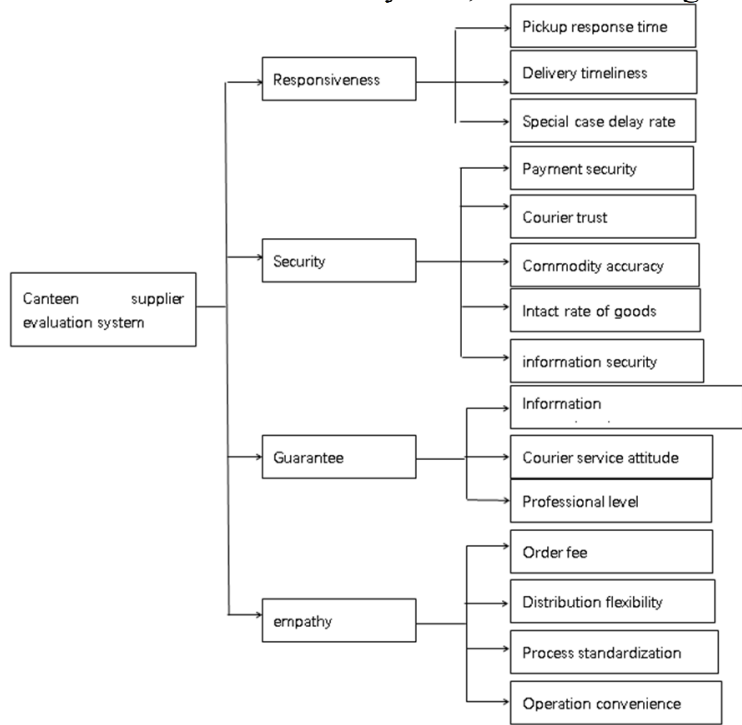

Fig 1. Crowdsourcing logistics service quality evaluation

(1) Security index system

Safety refers to the degree of customers' trust in parttime couriers, customers' trust in their own safety and customers' trust in the safety of their goods. The characteristics of part-time courier in crowdsourcing logistics mode are uncertain and uncontrollable, which will lead customers to question their own property safety and personal safety.

(2) Responsiveness

Responsiveness refers to the response speed of parttime couriers to customer demands, including key factors such as response time of picking up goods, timely delivery and delay under special circumstances.

(3) Guarantee

Guarantee refers to the ability of part-time couriers to provide customers with comprehensive and effective problem-solving ability, which also includes the service attitude of part-time couriers, professional quality of parttime couriers and other factors.

(4) Empathy

Empathy means that part-time couriers can spare no effort to think for customers, save customers' time from standardized operation process and flexible delivery, so as to effectively improve customers' perceived satisfaction with crowdsourcing logistics service quality and enhance the competitiveness of enterprises.

\section{SERVICE QUALITY EVALUATION OF CROWDSOURCING LOGISTICS}

\subsection{Weight Determination of Evaluation Index Based on AHP}

Analytic hierarchy process (AHP) is an operational research theory put forward by Professor Saaty of Pittsburgh University in the 1970s. It is an analytical method based on hierarchical weight decision. Analytic hierarchy process (AHP) is suitable for solving multiobjective and unstructured complex decision-making problems. The basic principle is: to hierarchize a complex problem, use less quantitative information to mathematicize the process, combine quantitative analysis with qualitative analysis, compare the indicators of the same level, establish a comparison matrix, judge its contribution rate to the indicators of the previous level, and so on Through comparative analysis of each layer, the weight value of each index can be obtained.

When using analytic hierarchy process to assign the index weight in the evaluation model, it can be roughly divided into the following steps:

(1) The complex problems are layered, and the hierarchical structure model is established

Firstly, the related factors of complex objective problems are decomposed into two-level index and threelevel index, which are called objective layer, criterion layer and index layer respectively.

(2) Establishment of contrast judgment matrix

When determining the importance of each index at each level, we need to use the consistent matrix method proposed by Saaty et al. Here, we use two indexes to compare with each other, rather than comparing all indexes together. The comparison judgment matrix represents the comparison of the relative importance of an index at the previous level, and the element AIJ in the comparison judgment matrix generally uses Saaty's 1-9 scale method.

(3) Calculate the weight vector and check the consistency

The eigenvector and the largest eigenvalue of each comparison judgment matrix are calculated, and the consistency index, consistency ratio and random consistency index are used for consistency test. If the consistency test is passed, the eigenvector is the weight vector; if the consistency test is not passed, the contrast judgment matrix needs to be re established to test the consistency ratio of the matrix, which can determine whether the index weight result calculated by AHP is reasonable.

(4) Calculate the weight of each index

There are two methods to calculate the weight of comparative judgment matrix: sum method and root method, namely standard column average method and geometric average method. In this paper, the standard column average method is used to calculate the weight value of each index. 


\subsection{Weight Determination of Evaluation Index Based on Entropy Weight Method}

The entropy method determines the objective weight of each index according to its variability. The entropy value of the index reflects the role of the index in the comprehensive evaluation. The larger the entropy value is, the smaller the weight is. The smaller the entropy value is, the larger the weight is. The main calculation steps of entropy method are as follows:

There are $n$ alternatives $U=\left\{X_{1}, X_{2, \ldots,}, X_{n}\right\} \quad(i=1,2, \ldots n)$ and $\mathrm{m}$ indexes $\mathrm{Q}=\left\{\mathrm{P}_{1}, \mathrm{P}_{2, \ldots}, \mathrm{P}_{\mathrm{m}}\right\} \quad(\mathrm{j}=1,2, \ldots \mathrm{m})$. Let $\mathrm{y}_{\mathrm{ij}}$ be the attribute value of index $P_{j}$ corresponding to scheme $X_{i}$. Because the dimensions of each index are different, the decision matrix needs to be normalized before making a decision, and the normalized matrix $\mathrm{R}=\left(\mathrm{r}_{\mathrm{ij}}\right)_{\mathrm{m}^{*} \mathrm{n}}$ (dimensionless).

$$
r_{\mathrm{ij}}=\frac{y_{\mathrm{ij}}}{\sqrt{\sum y^{2}{ }_{\mathrm{ij}}}}(1 \leq i \leq n, 1 \leq j \leq m)
$$

The entropy value $h_{j}$ of the index is calculated according to the formula:

$$
\mathrm{h}_{\mathrm{j}}=-\mathrm{k} \sum_{i=1}^{n} f_{i j} \ln \left(f_{i j}\right)
$$

Where $f_{i j}=\frac{r_{i j}}{\sum_{i=1}^{n} r_{i j}}, \mathrm{k}=\frac{1}{\ln \mathrm{m}}$

Finally, according to the formula:

$$
\beta_{j}=\frac{1-\mathrm{h}_{\mathrm{j}}}{\sum_{\mathrm{j}=1}^{\mathrm{m}}\left(1-\mathrm{h}_{\mathrm{j}}\right)}
$$

Calculate the index weight $\beta_{\mathrm{j}}$, where $0 \leq \beta_{\mathrm{j}} \leq 1, \sum \beta_{\mathrm{j}}=1$ 。

\section{CASE ANALYSIS OF SERVICE QUALITY EVALUATION OF CROWDSOURCING LOGISTICS}

Taking We select dada and Renren express to evaluate their service quality. Dada and Renren express are both platform distribution enterprises with crowdsourcing mode, but they are different in business mode and management. Dada platform serves hundreds of $\mathrm{O} 2 \mathrm{O}$ companies and platforms. The platform generates millions of orders every day on average. The number of part-time couriers registered on the platform exceeds 1.3 million, spanning nearly 30 second tier cities in China. The platform has strong security, timeliness and problemsolving ability of customer service center, which affects customers' perception of information platform and customer service center services. Renren Express provides a relatively perfect crowdsourcing logistics service management system and standardized logistics distribution process, such as monitoring the geographical location and node time of part-time couriers, according to whether the part-time couriers deliver the goods to customers in time, and objectively scoring the service quality after customers confirm that the goods are received correctly, so as to meet the demand of different businesses and consumers for crowdsourcing The personalized demand of logistics distribution service, and the customer must open the box to take photos before receiving the goods, take photos of the goods information, upload and check the information, directly affect the customer's perception of logistics process service.

In order to make the weight of the index more scientific and reasonable, this paper adopts the method of combining entropy method and analytic hierarchy process to get the final weight value of the index by arithmetic average the weight value of the index obtained by entropy method and AHP.

First, the first level Four index judgment matrix is established by AHP, as shown in Table 1 .

Table1. FIRST LEVEL INDEX JUDGEMENT MATRIX

\begin{tabular}{c|c|c|c|c}
\hline & Security & Responsiveness & Guarantee & empathy \\
\hline Security & 1 & 3 & 5 & 5 \\
Responsiveness & $1 / 3$ & 1 & 3 & 2 \\
Guarantee & $1 / 5$ & $1 / 3$ & 1 & $1 / 2$ \\
empathy & $1 / 5$ & $1 / 3$ & 2 & 1 \\
\hline
\end{tabular}

Due to space limitation, the calculation process is not listed one by one. The results are directly calculated by the analytic hierarchy process software Yaahp, and then the index weight value is calculated by entropy method according to the previous steps, and the final index weight value is obtained by arithmetic average with the analytic hierarchy process results, as shown in Table 2 .

\begin{tabular}{|c|c|c|c|}
\hline Index & Weight & Index & Weight \\
\hline Security & 0.535 & Delivery timeliness & 0.0834 \\
\hline Responsiveness & 0.124 & $\begin{array}{l}\text { Special case delay } \\
\text { rate }\end{array}$ & 0.083 \\
\hline Guarantee & 0.096 & $\begin{array}{c}\text { Information } \\
\text { comprehensiveness }\end{array}$ & 0.101 \\
\hline empathy & 0.135 & $\begin{array}{c}\text { Courier service } \\
\text { attitude }\end{array}$ & 0.062 \\
\hline Payment security & 0.111 & $\begin{array}{c}\text { Professional level of } \\
\text { courier }\end{array}$ & 0.054 \\
\hline $\begin{array}{l}\text { Rate of goods in } \\
\text { good condition }\end{array}$ & 0.102 & Order fee & 0.058 \\
\hline $\begin{array}{c}\text { Personal } \\
\text { information } \\
\text { security }\end{array}$ & 0.088 & Distribution flexibility & 0.062 \\
\hline $\begin{array}{c}\text { Commodity } \\
\text { accuracy }\end{array}$ & 0.069 & $\begin{array}{c}\text { Process } \\
\text { standardization }\end{array}$ & 0.087 \\
\hline Courier trust & 0.054 & $\begin{array}{c}\text { Operation } \\
\text { convenience }\end{array}$ & 0.004 \\
\hline Pick up time & 0.065 & & \\
\hline
\end{tabular}

Table2. WEIGHT OF CROWSSOURCING LOGISTICS SERVICE QUALITY EVALUATION INDEX

Next, the fuzzy comprehensive evaluation method is used to determine the evaluation results, and an evaluation group composed of 40 customers and representatives of the responsible persons of the logistics company is invited to give the evaluation values according to the five level percentage system, which are satisfied (90-100), average (60-90), dissatisfied (20-60), very dissatisfied (0-20), and the secondary indicators of dada and Renren express are 
evaluated one by one, Then use the weighted average to calculate the final score of each supplier, comprehensive ranking: dada is greater than Renren express. According to the weight, it is not difficult to see that the weight of platform security is the largest, and dada express is better in security, so security is still the most concerned factor in crowdsourcing logistics service quality evaluation at this stage.

\section{CONCLUSION}

By analyzing the demand of crowdsourcing logistics service quality evaluation, this paper selects a total of 15 specific index factors, establishes the crowdsourcing logistics service quality evaluation model, and evaluates two crowdsourcing logistics companies through the application of AHP and entropy weight method. Based on the evaluation results, this paper puts forward the corresponding improvement measures for crowdsourcing logistics enterprises, and puts forward some shallow suggestions for improving the service quality of crowdsourcing logistics.

\section{ACKNOWLEDGEMENT}

This work was supported by Anhui Xinhua university Comprehensive reform pilot project of logistics management under Grant No.2016zy068 and 2018 university level scientific research project of Quality Education Research Center for college students of Anhui Xinhua University under Grant No.IFQE201819 and 2019 Anhui University Humanities and social sciences research project under Grant No.SK2019A0728. The corresponding author of the article is Wang Dan-dan.

\section{REFENCES}

1. Yan Jie, Liu Renjing, Liu Han. Review of crowdsourcing research at home and abroad [J]. China Science and Technology Forum, 2017 (8): 5968

2. $\mathrm{Gu}$ Yanjing. Research on Evaluation and improvement strategy of third party logistics service quality based on e-commerce[J].Value engineering, 2017 (29): 27-29

3. Qiu Li. Construction of logistics distribution service quality evaluation system under B2C mode based on fuzzy analytic hierarchy process $[\mathrm{J}]$. Logistics science and technology, 2017 (6):6-11

4. Amorim P, Almada-Lobo B. The impact of food perishability issues in the vehicle routing problem[J].Computers\&amp; Industrial Engineering, 2014, 67(1):223-233.

5. Zou Y F, Xie R H, Liu G H. Safety reliability optimal allocation of food cold chain[J].Agricultural Sciences, 2013, 04(9):70-75. 